Provided for non-commercial research and education use. Not for reproduction, distribution or commercial use.

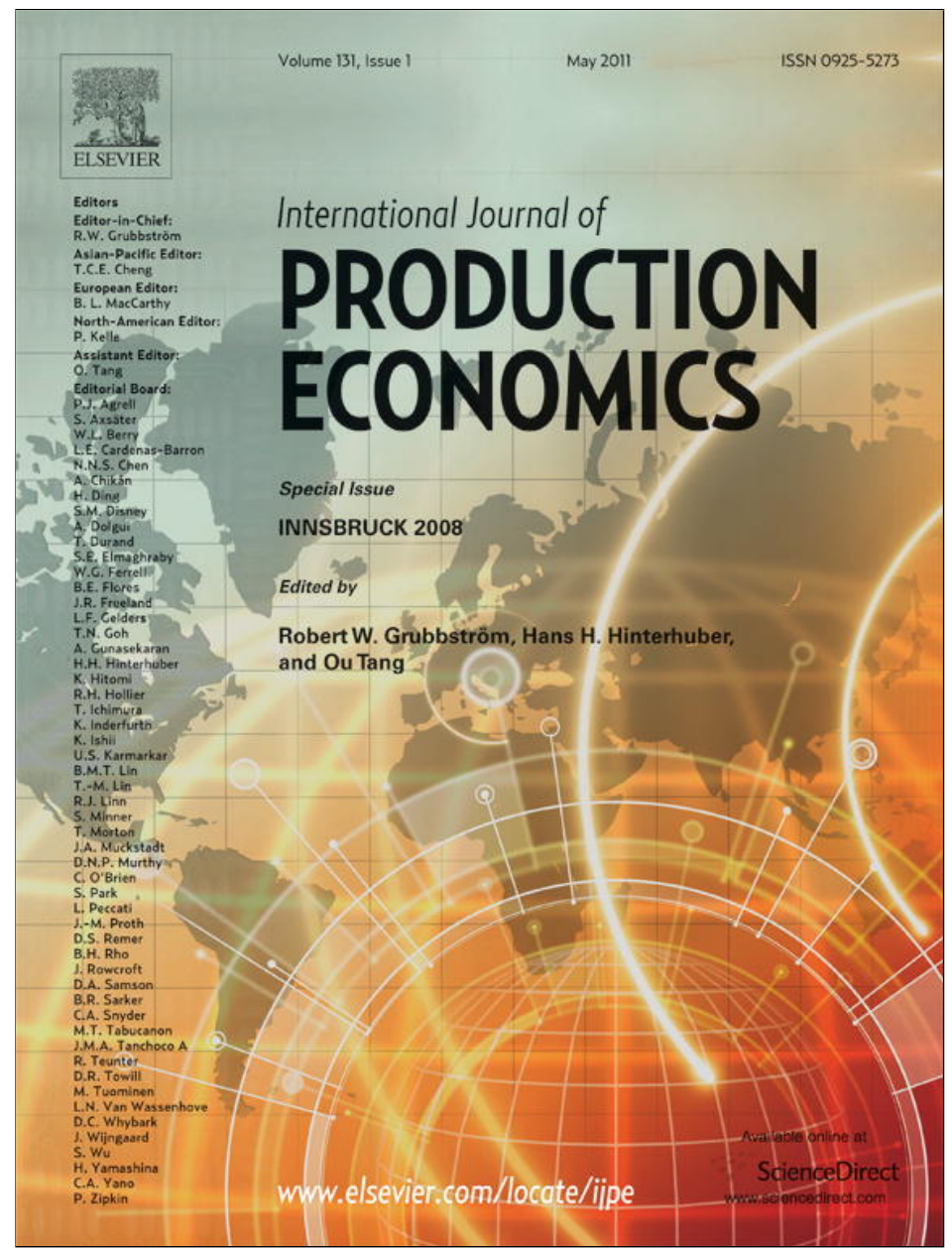

This article appeared in a journal published by Elsevier. The attached copy is furnished to the author for internal non-commercial research and education use, including for instruction at the authors institution and sharing with colleagues.

Other uses, including reproduction and distribution, or selling or licensing copies, or posting to personal, institutional or third party websites are prohibited.

In most cases authors are permitted to post their version of the article (e.g. in Word or Tex form) to their personal website or institutional repository. Authors requiring further information regarding Elsevier's archiving and manuscript policies are encouraged to visit:

http://www.elsevier.com/copyright 


\title{
Risk assessment and profit sharing in business networks
}

\author{
Giovanna Lo Nigro*, Lorenzo Abbate \\ DTMPIG, Dipartimento di Tecnologia Meccanica, Produzione e Ingegneria Gestionale, University of Palermo, Italy
}

\section{A R T I C L E I N F O}

\section{Article history:}

Received 1 July 2008

Accepted 17 August 2009

Available online 21 August 2009

\section{Keywords:}

Network organization forms

Network risk

Profit sharing

Shapley value

CAPM

\begin{abstract}
A B S T R A C T
Nowadays network is the preferred governance form to conduct economic transactions. Network solution allows to reach flexibility maintaining cost and quality level. Since network concept refers to a great variety of organizational hybrids it is possible to choose the one that fits better market requirements. The new trends in interorganization relationships push towards network solutions: companies are interested in relationships with partners and customers to overcome resource dependence, to enter too risky market or simply differentiate their business portfolio. The proposed research focuses on the network concept aiming at highlighting threats and opportunities to investigate the double nature of the risk concept. Network structures offer flexibility and higher profit as a consequence and business risk sharing opportunity.

These two aspects (profit and risk) are strictly related and have to be considered together to depict a complete scenario; this implies that risk assessment and management in network environment cannot neglect profit sharing or, in other words, that profit sharing mechanisms should use risk as driver. In this context our research proposes a methodology to measure risk taking into account network peculiarities; risk estimation is a basic step to evaluate the opportunity cost of capital needed to compute the network Net Present Value (NPV) that is assumed as base in the profit sharing process. The profit sharing process has been tackled using the Shapley value approach that is inspired to the fairness principle while the opportunity cost of capital is assessed using the Capital Asset Pricing Model (CAPM).
\end{abstract}

(c) 2009 Elsevier B.V. All rights reserved.

\section{Introduction}

Globalisation is a new challenge for firms and in particular for Small and Medium Enterprises (SMEs); indeed, on the one hand it represents a threat, since new emerging companies are likely to enter their domestic market but on the other hand, it offers the opportunity to enter new emerging and growing markets. In order to win this challenge firms can play the networking card; in fact, it is well acknowledged that networking can improve

\footnotetext{
* Corresponding author.

E-mail addresses: glonigro@dtpm.unipa.it (G. Lo Nigro). abbate@dtpm.unipa.it (L. Abbate).
}

firms' effectiveness and efficiency which is absolutely necessary to win the globalisation battle.

From Powell's (1990) seminal work networked organisations have emerged as a new enterprise pattern able to better match the new competition arena requirements. From then many papers have addressed hybrids from an economic point of view (Menard, 2004), from an organisational point of view (Grandori and Soda, 1995), and from a performance point of view (Mazzarol, 1998). This last point is of particular interest; indeed, an underlying assumption concerning networks is that hybrids are especially good for SMEs. In fact, through networks, SMEs are able to overcome some of the limitations due to their size (achieving scale and scope economies coming from resources pooling) by maintaining the advantages coming 
from being small (reactiveness, proactiveness and so forth). On the other hand, network solutions imply some shortcomings: a firm that decides to link its business to other firms accepts a sort of dependence from them. Such dependence can lead to in opportunistic behaviour and then the risk of not achieving the desired objectives can arise. In order to encourage firms to bear this risk a proper profit sharing mechanism is needed. Usually, network solutions allow to achieve a better, but more uncertain, solution then it needs to estimate the NPV of the project taking into account either the higher estimated cash flows both the higher expected rate of return. In literature it is possible to find research on network risk but the problem is not investigated with a quantitative approach: our aim is to quantify the network risk. Moreover a fair profit sharing mechanism should guarantee the partners that their effort in the cooperation will be rewarded: in order to do that we propose to use the Shapley value properly adapted to our settings.

In Section 2 a brief literature review is reported: in particular Section 2.1 analyzes drivers that push towards networking and Section 2.2 tackles with the definition of risk in network environment; in Section 3 and 4 the methodologies to measure the network risk and to fix the profit share for each partner are respectively explained; Section 5 shows a numerical example aimed at explaining how to implement the methodologies proposed in the two previous sections; Section 6 is dedicated to conclusions and further developments.

\section{Literature review}

Network solution in organization field aims at realizing coordination among resources belonging to distinguished companies with the objective of pursuing economic benefits. The range of organization solutions embraced in this definition of network is wide: from supply chain relationships to strategic joint ventures. The research paths in this field are aimed at answering to the following questions: what is a network? does it exist a common background for all the different organization models included in the network paradigm? what are the recurrent reasons that push firms to join a network? how should be designed a network? which are the parameters involved? Other questions originate if the risk perspective is adopted: in network environment how can the risk be defined? how can it manage? what are the main drivers for network risk?

\subsection{Network organization drivers}

Menard (2004) answers to the first group of questions: he analyzes hybrids following the micro-analytical direction traced out by Coase (1991) and highlights three headings encapsulated regularities in hybrids: pooling, contracting and, competing. The choice of a particular arrangement among the available one essentially depends on mutual dependence and uncertainty while the governance model decision involves contractual hazards, revenues sharing and, enforcement issues.
As stated in Hallikas et al. (2004) through networking companies aim at reducing financial and technological risks improving their competitive advantage through deeper specialization. Indeed, hybrids seem to exist because markets are perceived as unable to adequately bundle the relevant resources and capabilities, while integration in a hierarchy would reduce flexibility by creating irreversibility and weakening incentives. On the other hand, pooling resources in network organisation allows to keep strong incentives while maintaining organisation flexibility, specialization creates dependency on resources belonging to other companies, dependency increases outcome uncertainty, as a conclusion networking creates additional risks, the so called cooperation risks (Link and Marxt, 2004).

Harland et al. (2003) locate in product/service complexity the reason of outsourcing which causes changes in industry structure and, together to e-business, sustains globalisation. The combined effects of the above mentioned phenomena have caused supply network to become increasingly complex and dynamic characterized by a complex flow of tangible and intangible features: this tight interdependency among resources belonging to different firms creates a huge amount of compliance assessment points which are potential sources of risk. Ojala and Hallikas (2006) deal with the investment decision making problem in supplier networks considering the risk as a discriminator to accept or refuse investment; they match risk investment degree (depending on investment size and asset specificity) with the investment strategic importance to decide if undertake or not the investment.

These considerations are too often acted as inhibitor elements in the networking decision while it is necessary to accompany them with network opportunities in order to foster networking because of its importance as key element to compete in the today market.

\subsection{Risk in network organization}

Risk in networking requires for a dedicated study because of its peculiarities. Network risk has been the object of research study: many researchers have classified risks originating in network environment and this is a preparatory step to risk management.

In the academic literature risk is defined as "the variance of probability distribution of outcomes" (March and Shapira, 1987). The achievement of a goal in a network environment depends on partners' relationship behaviour as well as objective business environment. This leads to a multi- dimensional construct for risk because of multi dimension of factors influencing outcomes in a network context. Baird and Thomas (1990) have defined risk from eight different perspectives: among these perspectives they mention variability of returns even if all the other risk characteristics affect, in the short or long term, firm financial performances. Other authors are addressed risk characteristics and definition study (Shapira, 1995; Yates and Stone, 1992) the emerging issue 
in these researches is that all the characteristics impact on firm financial results.

Das and Teng (2001) in their work split network risk in performance and relational risk, indicating the second as depending on relationship abilities of network partners. Additional sources of risk in network context are indicated in Link (2001) and located especially at culture level.

Hallikas et al. (2002) investigate production network risk and to pursue this issue divide risk in four classes; their approach is a dyadic approach, that is they assume the buyer or supplier point of view to assess network risk and prioritize it. On the contrary, Harland et al. (2003) propose a supply network risk tool to identify, assess and manage risk to support the single partner decision making process concerning network evaluation; they claim they want to adopt a holistic approach but they envisage that decisions coming from partners could not agree and give rise to destabilizing of the network at some point. Link and Marxt (2004) besides assuming a holistic and systematic approach, integrate risk and chance sharing using chance to counterbalance risk assumption. In order to handle correctly risk its positive side has to be taken into account: more risky activities can be considered suitable depending on their profitability (it depends on decisor making risk aversion).

Usually to evaluate networking convenience a static perspective is assumed: economic theories are based on cost-based considerations neglecting the evolutionary side of networking or its long term consequences (immaterial factors that can cause financial losses in the long run hard to convert into monetary value (Hallikas et al., 2004)).

To overcome this limitation Das and Teng (2001) take into account risk consideration in an early phase of network constitution: they suggest a risk perception model to drive alliance structure choice that include several risk antecedents (psychological traits such as trust propensity, locus of control, future orientation and situational factors such as alliance history, partner asymmetries, shared $R \& D$ efforts). In a previous paper (Das and Teng, 1996) they classify network risk in relational and performance risk. In their classification relational risk concerns the probability and consequences that a partner does not commit to the alliance in the agreed manner. Performance risk refers to those factors that may jeopardize the achievement of strategic objectives, given that the partners cooperate fully. They consider independent the two type of risk and propose to fit the best network governance depending on the amount of relational and performance risk forecasted. In particular they classify network in equity (joint ventures and minority equity network) and non-equity network (one and bilateral contract) investigating the ability of each structure to tackle with relational and performance network. In fact, as emerged in Yoshino and Rangan (1995) study managers believe that success or failure of alliances hinge on their structures, moreover, they find that different partners in the same industry choose different alliance structure for the same purpose; then alliance structure is not mandatory based on alliance strategic scope.
The literature analysis (Link, 2001) seems to conclude that when the networking is chosen to run a business the consequent risk is higher than the risk related to the same business run by a single company, even if resource dependence theory suggests strategic alliance to share risk and networking is a tool to enter too risky market. If networking assures a higher rate of investment return in fact the risk is supposed to be higher, otherwise this conclusion is not obvious and risk definition would need a deeper investigation.

In his research Zsidisin (2003) finds out that companies define supply risk taking into account direct losses as well as opportunity cost. As a consequence firm should formulate its alternatives to networking to evaluate if risk rise is acceptable or not; in Lo Nigro et al. (2007) authors consider discarded alternatives in order to properly formulate opportunity cost and define partner risk.

As already mentioned, Das and Teng (2001) distinguish performance risk and relational risk as components of network risk. Single firm effort and interfirm cooperation are alternative ways to carry out a project. A shared performance risk via an alliance will usually be lower than the performance risk of a project carried out by one firm. By pooling resources of several specialised firms the likelihood of success is enhanced. In as much, as the partners have contended with performance risk of a project, strategic alliances constitute an effective way to control that performance risk. Then it is useful to split also performance risk as defined in Das and Teng (2001) between performance risk as the risk incurred by a single firm carrying out a project and a network performance risk referred to the network risk when the partners cooperate fully (Lo Nigro et al., 2007). When the network solution is embraced relational risk occurs. As explained in Lo Nigro et al. (2007), risk is modified shifting from a single firm conducting the business to a network performing the same business; it is possible to model risk escalation as sum up of contribution from network performance risk and network relational risk.

Relational risk is related to lack of trust, inaccurate information sharing and asymmetry in reciprocal position that causes dependency (a partner acts as captive in the relationship) (Ojala and Hallikas, 2006).

Smallman's categorization of direct and indirect risks (Smallman, 1996) is helpful in the considered environment because it is worthwhile to be aware that risk may be partly influenced by an organization and individuals within it and partly by events beyond their influence. In this context risk can be categorised in direct and indirect referring to the network influence in their occurrence. Hence certain amount of network risk is inherent the business while the complementary part is related to networking choice.

Combining Das and Teng (2001) classification with Smallman (1996) categorization using network as risk object, Lo Nigro et al. (2007) analyse risk basing on risk decomposition as shown in Fig. 1.

In order to clarify the proposed risk decomposition, it can be observed that network risk can be considered the combination of relational and performance risk: performance risk can be explained by taking into account both 


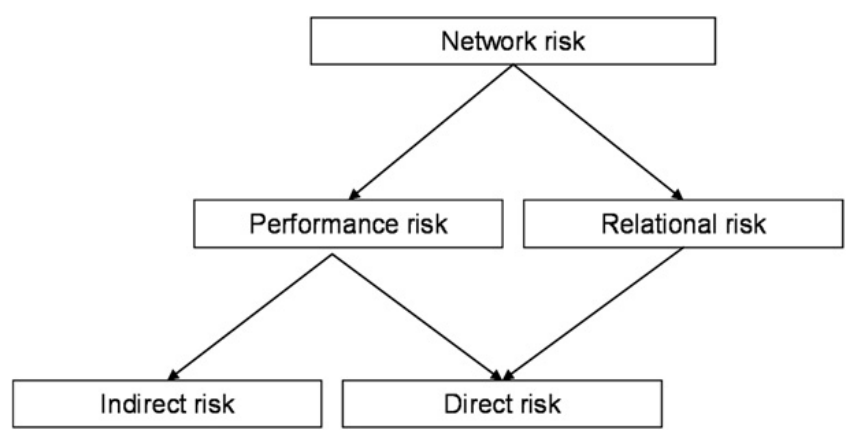

Fig. 1. Network risk decomposition (Lo Nigro et al., 2007).

objective business conditions (indirect performance risk) and network behaviour (direct performance risk). Indirect performance risk is the part of network risk not dependent on network characteristics, a systematic risk, while direct risk are directly related to network solution then it is an unsystematic or specific risk. It is worthwhile to observe that direct risk contribution could reduce performance risk.

Our research starts from this decomposition to quantitatively estimate network risk and the rate of return of network project useful to define a fair revenue for each participant.

Risk management basically follows two strategies: individuate actions to fight risk consequences and try to reduce a priori risk sources. The mandatory stage in both cases consists in risk evaluation. Most companies develop plans to protect against recurrent, low-impact risks (operational risk) in their supply chains; many, however, ignore high-impact, low-likelihood risks (disruptive risk).

We aim to support risk manager in checking the effects of his decisions on operational and disruptive risk or alternatively in evaluating network risk in the assessment step of his work.

\section{Measure the risk in business network}

In order to manage risk it is helpful to find out its sources. Hallikas et al. (2006) individuate in asset specificity, market inefficiency, knowledge appropriability and timing misalignment among partners the risk sources.

Spekman et al. (2002) state that the same uncertainty that pushes firms to cooperate also offers partners a chance to behave opportunistically.

Ring and Van de Ven (1992) identify two distinct sets of uncertainty in strategic alliances: uncertainty regarding future states of nature and uncertainty whether partners will be able to rely on trust. In this classification it is not considered uncertainty regarding the alliance ability to cope with the unpredictable events. In alliances devoted to complex environment contracts cannot cover all the possible states of nature then it should behold how to face with unforeseen events.

In contrast with the dyadic approach that focuses on focal firm to assess the risk but, as main drawback, it can find out a non optimal solution for the network, it is possible to measure risk considering the network per- spective. This does not mean neglect network peculiarities; that is the risk assessment has to take into account network competencies.

This research focuses its attention on risk measured by expected results variability.

In the network environment it seems easier and also more useful to manage it to define the global network risk than to define the risk borne by each partner.

The problem of network risk estimation has been treated in literature in a qualitative form; it is possible to find out drivers that affect positively the risk (the risk increases) and drivers that affect the risk in the opposite sense. In the other hand the quantitative estimation does not receive particular attention, even if the qualitative findings can support the quantitative approach.

Our aim is to estimate risk as variability in the expected results; in the corporate finance area project with higher variability in expected cash flows are required a higher rate of return of capital.

In the finance field the cost of capital or rate of return is estimated using various models; the most used is the Capital Asset Pricing Model (CAPM) (Sharpe, 1964). The CAPM is an equilibrium theory based on the theory of portfolio selection. In the present application CAPM is used to estimate the cost of capital for the network investment.

The CAPM formulation is shown below:

$r_{i}=r_{r f}+\beta_{i} \cdot\left(r_{m}-r_{r f}\right)$

where $r_{i}$ is the rate of return for a generic stock $i$; $r_{r f}$ is the rate of return of the risk free investment; $r_{m}$ is the rate of return for the market; $\beta_{i}$ is the sensibility to stock $i$ to market trends.

For the aim of our research $i$ represents the considered network $(N)$ and to estimate $r_{N}$ it needs $\beta_{N}$ (the CAPM $\beta$ factor for the network $N$ ).

Managing network risk is difficult because risk components are often interconnected. As a result, actions that mitigate one risk component can end up exacerbating another (Chopra and Sodhi, 2004); risk decomposition could help to properly evaluate the effect of hedging solution on each part of it and then avoid their overestimation.

Let us indicate with $\beta_{I}$ the CAPM $\beta$ factor for the industry to which the considered network $N$ belongs to; this factor takes into consideration the indirect performance network risk because considers the sources of risk that do not depend on network arrangement.

Basing on the risk decomposition shown in Fig. 1 that identifies three network risk components. We estimate $\beta_{N}$ with a bottom up procedure. In fact, $\beta_{N}$ can be estimated by $\beta_{I}$ if we are able to quantify the effect that direct network risk should have on $\beta_{I}$. In the adopted decomposition model for the network risk, direct risk is articulated in relational and performance direct risk. We propose to estimate $\beta_{N}$ by a levering/unlevering process on $\beta_{I}$ through two $\beta$ s parameters related to relational $\left(\beta^{R}\right)$ and performance $\left(\beta^{P}\right)$ network direct risk.

$\beta_{N}=\beta_{I} \cdot \beta^{R} \cdot \beta^{P}$ 
Relational risk refers to the variability induced in network performance when partners do not respect commitments; literature suggestions reported in Section 2 led to conclude that this may happen when potential opportunism is high, relational uncertainty is high (incomplete contract because of unpredictable events) and trust (previous experience) and reputation importance are low.

Table 1 shows the sub-factor for $\beta^{R}$; the second column shows the source of risk for the factor indicated in the first column, while the third column states the correlation between the source level and $\beta^{R}$, e.g. if the potential opportunism is high $\beta_{1}^{R}$ is also high. Each sub-factor can be expressed in a $l$-point Likert scale (ranging in the interval $[1-l])$ that measures the degree of truth of the related statement (Table 2 ) and $\beta^{R}$ can be calculated as follows:

$\beta^{R}=\frac{\boldsymbol{t}}{3 \cdot \boldsymbol{l}} \sum_{i=1}^{3} \beta_{i}^{R}$

where $l$ is the upper bound for the Likert scale adopted and $t$ is a threshold greater than one that expresses the

Table 1

$\beta^{R}$ sub-factors.

\begin{tabular}{lll}
\hline Factor & Source & Effect on $\beta^{R}$ \\
\hline$\beta_{1}^{R}$ & Potential opportunism & positive \\
$\beta_{2}^{R}$ & Relational uncertainty & positive \\
$\beta_{3}^{R}$ & Trust and reputation importance & negative \\
\hline
\end{tabular}

Table 2

$\beta^{R}$ sub-factors assessment.

\begin{tabular}{lll}
\hline Factor & Statement & Range \\
\hline$\beta_{1}^{R}$ & Potential opportunism is high in the network & {$[1-l]$} \\
$\beta_{2}^{R}$ & Relational uncertainty is high in the network & {$[1-l]$} \\
$\beta_{3}^{R}$ & Trust and reputation is not important at all in the & {$[1-l]$} \\
& network & \\
\hline
\end{tabular}

sensitivity of $\beta_{N}$ to $\beta^{R}$ that depends on industry characteristics and represents the value of $\beta^{R}$ when all $\beta_{i}^{R}$ are equal to their maximum value $(l)$.

Therefore the effect of $\beta^{R}$ on $\beta_{N}$ can vary from a neutral one $\left(\beta^{R}=1\right)$ to a levering one $\left(\beta^{R}=\mathrm{t}\right)$.

Direct performance risk considers variability originates because of network adoption and in case of perfect commitment. Usually the effect of $\beta^{P}$ on $\beta_{N}$ is a mitigating or unlevering one, then $\beta^{P}$ varies in the range $[0-1]$ (lower values of $\beta^{P}$ mean that network is able to strongly reduce risk, $\beta^{P}=1$ means that network plays a neutral role on the total performance risk).

According to risk definition an effective risk management is empowered by the ability to face with changes, i.e. to be flexible (flexibility is the capacity to react or pro-act to change). One of the most acknowledged benefits of networking is the possibility to maintain an agile structure competing in challenging markets. Teece et al. (1997) define dynamic capabilities as the firm's ability to integrate, build and reconfigure internal and external competencies to address rapidly changing environments. Then networks seem to guarantee a higher level of flexibility respect a single company able to compete like the network; this flexibility allows the network to reduce its results variability then we can guess that $\beta^{P}$ has a mitigating effect on $\beta_{I}$.

In order to estimate $\beta^{P}$ we adopt the Supply Chain Management perspective proposed by Tang (2006) even if a network is a broader concept. Tang proposes four basic approaches to mitigate the impact of supply chain risks: network should coordinates transaction with upstream (supplier) and downstream (customer) partners to obtain an efficient supply of input of any nature and to influence demand in a favourable manner, moreover network could intervene in product characteristics to exploit partner specificity and to make easier market requirement accomplishment, finally network should manage partner private information in order to achieve a competitive advantage (Fig. 2).

Therefore $\beta^{P}$ can be split in four sub-factors and each of them has a related statement (Table 3); the degree of truth

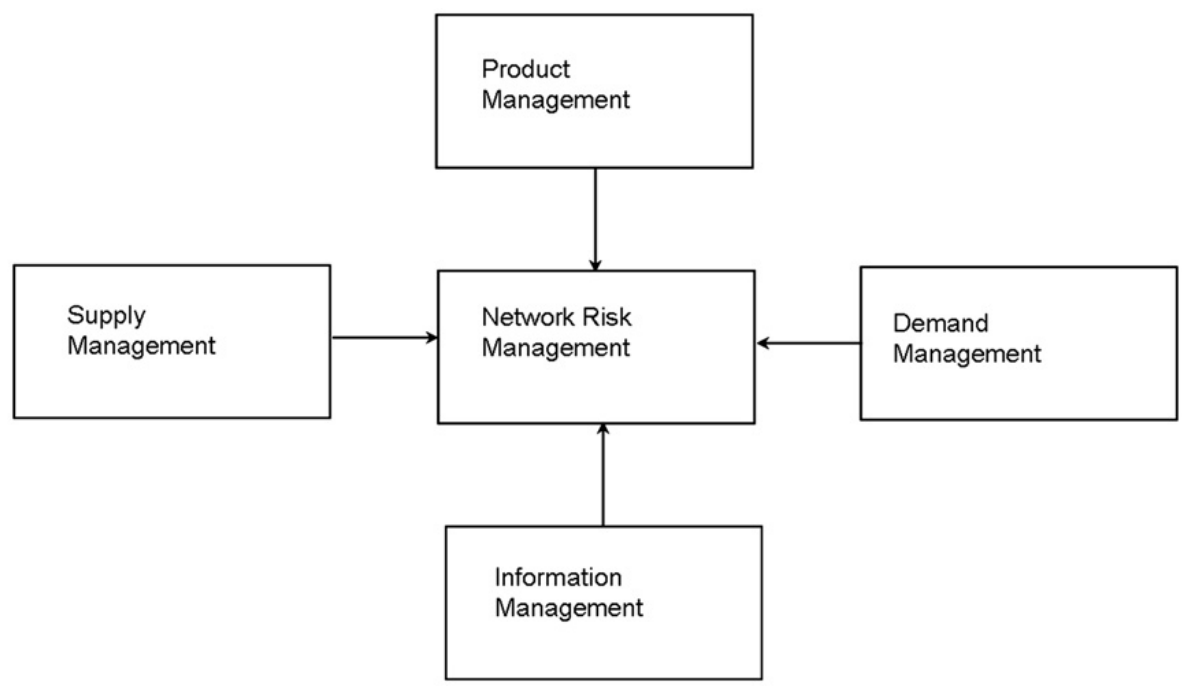

Fig. 2. Approaches for managing network direct performance risk (Tang, 2006). 
Table 3

$\beta^{P}$ sub-factors assessment $r$.

\begin{tabular}{lll}
\hline Factor & Statement & Range \\
\hline$\beta_{1}^{P}$ & $\begin{array}{l}\text { Network arrangement does not allow to improve } \\
\text { product management }\end{array}$ & {$[0-1]$} \\
$\beta_{2}^{P}$ & $\begin{array}{l}\text { Network arrangement does not allow to improve } \\
\text { information management }\end{array}$ & {$[0-1]$} \\
$\beta_{3}^{P}$ & $\begin{array}{l}\text { Network arrangement does not allow to improve } \\
\text { supply management }\end{array}$ & {$[0-1]$} \\
$\beta_{4}^{P}$ & $\begin{array}{l}\text { Network arrangement does not allow to improve } \\
\text { information management }\end{array}$ & {$[0-1]$} \\
\hline
\end{tabular}

of each statement can be expressed in the range $[0-1]$

( 1 if the statement is true).

To calculate $\beta^{P}$ Eq. (4) can be used

$\beta^{P}=\frac{1}{4} \sum_{i=1}^{4} \beta_{i}^{P}$

Finally using Eq. (2), $\beta_{N}$ can be estimated and Eq. (1) allows calculating $r_{N}$.

\section{Profit share in business network}

The profit sharing mechanism should be based on equality principles; each partner should be aware that the received profit is commeasured to the effort made for the collaboration. Shapley value (Shapley and Shubik, 1954) has already been used to fulfil such kind of requirements (Lo Nigro et al., 2005). The Shapley value aims at measuring the contribution value of a participant in a collaborative group through the mean value added to the group.

According to Lamming (1993) value analysis and value creating potential exploration of different phases in the network history should drive network establishment; in his work Lamming addresses supply chain relationship and states that long term relationship main driver should be added value of supplier than reducing purchasing costs. Generalizing Lamming proposition it can be affirmed that network constitution main drivers should have a long term orientation (taking into account network evolution opportunities) rather than pursue just risk reduction.

Network value embracing a long term perspective can be evaluated through its NPV; to do that cash flows and cost of capital have to be estimated.

In the game theory field it is desirable to have a solution concept for cooperative games that results in a unique outcome and hence has a reasonable predictive power (as the Nash equilibrium in non-cooperative games). Shapley (Tang, 2006) offers an axiomatic approach to the solution concept that is based on three quite intuitive axioms. First, the value of the player should not change due to permutations of players, i.e. only the role of the player matters and not names or indices assigned to players. Second, if a player's added value to the coalition is zero then this player should not get any profit from the coalition, or in other words only players generating added value should share the benefits. Finally, the third axiom requires additivity of payoffs.

The surprising result obtained by Shapley is that there is a unique equilibrium payoff (called the Shapley value) that satisfies all three axioms.

There is only one payoff function $\pi$ for a characteristic function $v$ that satisfies the three axioms. It is defined by the following expressions for $\forall i \in N$ :

$\pi_{i}(v)=\sum_{S \subseteq N} \frac{|S| !(|N|-|S|-1) !}{|N| !}(v(S \cup\{i\})-v(S))$

The Shapley value assigns for each coalition (network in our case) and to each player his marginal contribution $v(S \cup\{i\})-v(S)$ where $S$ is a random coalition of agents preceding $i$ and the ordering is drawn randomly. To further explain (see Myerson, 1997), suppose players are picked randomly to enter into a coalition. There are $|N|$ ! different orderings for all players, and for each set $S$ that does not contain player $i$ there are $|S| !(|N|-|S|-1)$ ! ways to order players so that all of the players in $S$ are picked ahead of player $i$. If the orderings are equally likely, there is a probability of $|S| !(|N|-|S|-1) ! /|N|$ ! that when player $i$ is picked he will find $S$ players in the coalition already. The marginal contribution of adding player $i$ to coalition $S$ is $v(S \cup\{i\})-v(S)$. Hence, the Shapley value is nothing more than a marginal (expected) contribution of adding player $i$ to the coalition. Due to its uniqueness, the concept of the Shapley value has found numerous applications in economics and political sciences (Aumann, 1994).

As observed in Ghosh and John (1999) claiming quasi rents in network is an issue as important as creating it; several studies suggest that the solution is based on a mix of observable components and discretionary decisions and both are based on fair principles.

In our application $N$ is the set of partners, $S$ is the generic subset of $N, v$, the characteristic function, is the value of the business the network wants to undertake and $\pi_{i}$ the pay off, is the network $v$ 's portion to assign to partner $i$. Let us to consider for sake of simplicity a set $N$ of three partners (namely A, B and C) that want to join in a network to carry out an economic initiative. This initiative should be pursued by different economic actors: individually by each partner, by any pair of partners or by all together; the resulting value will change accordingly. How should the achieved pay off be shared?

The list of different orderings for all the players is presented in Table 4 and for each set of $S$, for example, two elements that does not contain, for example, A (just one in the considered case) there are 2 ways to order partners so

Table 4

Possible orderings for the set $N=\{A, B, C\}$.

\begin{tabular}{ll}
\hline Ordering number & Permutation \\
\hline O1 & ABC \\
O2 & ACB \\
O3 & BAC \\
O4 & BCA \\
O5 & CAB \\
O6 & CBA \\
\hline
\end{tabular}


that the partner in $S$ are picked ahead of A (O4 and 06) and each of them has a probability of $1 / 3$. It is possible to estimate the marginal contribution of $A$ to the network as the difference between the value of the network of three partners and the value of the network whose elements are B and C. By iterating the procedure for $|S|=1$ and $S=\{\emptyset\}$ the Shapley value can be computed. Therefore the cash flows and the related cost of capital for each economic actor considered have to be estimated; the methodology proposed in the previous section supports in the second task.

It is possible to calculate the Shapley value for the three partners; these values are computed basing on the expected cash flows but, as it is known, these cash flows are affected by uncertainty then the Shapley value $\pi_{i}(v)$ can support profit sharing decision fixing the percentage of the effectively achieved profit to assign to the partner $i$ $\left(P P_{i}\right)$.

$P P_{i}=\frac{\pi_{i}(v)}{\sum_{i} \pi_{i}(v)}$

This modus operandi leads to various advantages that allow to overcome some drawbacks of alternative methods used to share pay off. It is a fair and impartial method that assigns the payoff basing on the individual contribution. Profit sharing is a crucial aspect in networking because firms engage in network because they expect a quasi rent from their investment (Menard, 2004). Moreover incentive issues can help to disincentive partners from opportunistic behaviour.

\section{Numerical example}

Let us introduce a numerical example with explicative aim. Let us consider the automotive industry for which a beta value of $1.3\left(\beta_{I}\right)$ has been estimated in January 2009 for the USA market (http://pages.stern.nyu.edu/ adamodar/pc/ datasets/betas.xls). Let us suppose that a network of three firms (namely A, B and C) can be built to conduct a business. Using the data reported in Table 5 the beta value for the network can be calculated using the proposed method illustrated in Section 3.

These data in a real case should be obtained interviewing managers with a deep knowledge about the considering network (in the numerical example a 5 points Likert scale has been adopted for $\beta_{i}^{P}$ ). Using a threshold value $t$ equals to 2 , the betas factors can be estimated and the following values are obtained:

$\beta^{P}=0.625 \beta^{R}=1.33 \beta_{N}=1.083$.

The $\beta_{N}$ is fundamental to estimate $r_{N}$ that has to be used to evaluate the NPV for the network (cash flows are to be estimated and the NPV has to be calculated).

Table 5

Input data for the numerical example.

\begin{tabular}{lllllll}
\hline$\beta_{1}^{P}$ & $\beta_{2}^{P}$ & $\beta_{3}^{P}$ & $\beta_{1}^{R}$ & $\beta_{2}^{R}$ & $\beta_{3}^{R}$ & $\beta_{4}^{R}$ \\
\hline 3 & 2 & 5 & 0.6 & 0.8 & 0.7 & 0.4 \\
\hline
\end{tabular}

Table 6

Characteristic function.

\begin{tabular}{lc}
\hline $\boldsymbol{S}$ & $v(\boldsymbol{S})\left(\mathbf{1 0}^{\mathbf{5}} €\right)$ \\
\hline $\mathrm{A}$ & 50 \\
$\mathrm{~B}$ & 30 \\
$\mathrm{C}$ & 60 \\
$\mathrm{AB}$ & 100 \\
$\mathrm{AC}$ & 120 \\
$\mathrm{BC}$ & 110 \\
$\mathrm{ABC}$ & 150 \\
\hline
\end{tabular}

Table 7

Evaluation of $\pi(A)$.

\begin{tabular}{llll}
\hline $\boldsymbol{S}$ & $v(\boldsymbol{S} \cup\{\boldsymbol{A}\})$ & $v(\boldsymbol{S})$ & Probability (admissible sets) \\
\hline$S=0$ & $v(A)=50$ & $v(\emptyset)=0$ & $\frac{2}{6}\{(A B C),(A C B)\}$ \\
$S=1$ & $v(B A)=100$ & $v(B)=30$ & $\frac{1}{6}\{(B A C)\}$ \\
& $v(C A)=120$ & $v(C)=60$ & $\frac{1}{6}\{(C A B)\}$ \\
$S=2$ & $v(A B C)=150$ & $v(B C)=110$ & $\frac{2}{6}\{(B C A),(C B A)\}$ \\
\hline
\end{tabular}

Table 8

Results for $\pi$ e PP values.

\begin{tabular}{llllll}
\hline$\pi(\boldsymbol{A})\left(\mathbf{1 0}^{\mathbf{5}} €\right)$ & $\pi(\boldsymbol{B})\left(\mathbf{1 0}^{\mathbf{5}} €\right)$ & $\pi(\boldsymbol{C})\left(\mathbf{1 0}^{\mathbf{5}} €\right)$ & $\boldsymbol{P P}(\boldsymbol{A})$ & $\boldsymbol{P P}(\boldsymbol{B})$ & $\boldsymbol{P P}(\boldsymbol{C})$ \\
\hline 51.67 & 36.67 & 61.67 & $34.44 \%$ & $24.44 \%$ & $41.11 \%$ \\
\hline
\end{tabular}

In order to establish the portion of the network pay off to assign to each partner (A, B and $C$ ) the method proposed in Section 4 can be applied. In Table 6 the values for the considered characteristic function are reported: each value represents the NPV related to the alternative of realising the business for which the network has been built with the corresponding set of partners (i.e. if the business would be done by A alone a NPV equals to $€ 50 \cdot 10^{5}$ should be achieved). Each value is then a NPV and to calculate it the correct $r$ (opportunity cost of capital) has to be employed; for the set $S=(A, B, C)$ the value of $r$ is $r_{N}$ and can be found out using the CAPM with the value of beta $=\beta_{N}=1083$. In the other cases the method reported in Section 3 and used above to calculate $\beta_{N}$ can be used.

To find out $P P_{A, B, C}$ (Eq. (5)) Shapley values for $A, B$ and $C$ are needed; they can be estimated using Eq. (4). The possible orderings for the set $N=\{A, B, C\}$ are those reported in Table 4 . Table 7 reported the values of $v$ necessary to evaluate $\pi(A)$.

Table 8 shown the values of $\pi(A), \pi(B), \pi(C)$ and $P P(A), P P(B), P P(C)$. As a result the network partners know that the economic pay off will be shared using the percentage indicated by $P P(A), P P(B), P P(C)$.

\section{Conclusions}

Networking is increasingly adopted by firms to compete in globalized market. In assessing network relationship a critical factor is represented by risk. 
In order to manage network risk it is helpful to decompose it; often risk managers efforts are not effective because of the multifaceted consequence of an hedging action. Therefore, instead of estimate the network risk as a whole it is fundamental to isolate its components and highlight the various effects of a decision aiming at controlling the risk. The risk decomposition has also been helpful in the risk computation. The paper wants to give a contribution by suggesting a methodology to compute risk in network environment. Such methodology encapsulates the CAPM to assess the cost of capital in firms networking investments and it can be customised by varying the subfactors considered and it allows to use experts' experience to evaluate the risk. Risk and cost of capital estimation is a preparatory step to tackle with the profit sharing problem. The proposed methodology is able to fix in a fair way the percentage of profit to assign to each partner and it allows to consider the evolution of the network and the double nature of the risk (opportunity, that is higher cash flows and, uncertainty, that is higher cost of capital).

Further developments will consider real option theory in the network value estimation because one of the main benefits of network solution is its ability to reconfigure itself to undertake new profitable challenges.

\section{Acknowledgements}

Authors are grateful to the anonymous reviewers for their helpful suggestions that concretely have contributed to ameliorate the paper from its original version.

\section{References}

Aumann, R.J., 1994. Economic applications of the Shapley value. In: Mertens, J.-F., Sorin, S. (Eds.), Game-Theoretic Methods in General Equilibrium Analysis. Kluwer Academic Publishers, Dordrecht, pp. 121-133.

Baird, I.S., Thomas, H., 1990. What is risk anyway?. In: Bettis, R.A., Thomas, H. (Eds.), Risk, Strategy, and Management. JAI Press, Greenwich, CT, pp. 21-52.

Chopra, S., Sodhi, S.M., 2004. Managing risk to avoid supply chain breakdown. Sloan Management Review Fall, 53-61.

Coase, R.H., 1991. The institutional structure of production, Alfred Nobel Memorial Prize Lecture in Economic Science, Nobel Foundation, reprinted in: American Economic Review, vol. 82, 1992, pp. 713-719.

Das, T.K., Teng, B., 1996. Risk types and inter-firm alliance structures. Journal of Management Studies 33, 827-843.

Das, T.K., Teng, B., 2001. A risk perception model of alliance structuring. Journal of International Management 7, 1-29.

Ghosh, M., John, G., 1999. Governance value analysis and marketing strategy. Journal of Marketing 63, 131-145.

Grandori, A., Soda, G., 1995. Inter-firm networks: antecedents, mechanisms and forms. Organisation Studies 16 (2), 183-214.
Hallikas, J., Virolainen, V.-M., Tuominen, M., 2002. Risk analysis and assessment in network environment: a dyadic case study. International Journal of Production Economics 78, 45-55.

Hallikas, J., Karvonen, I., Pulkkinen, U., Virolainen, V.-M., Tuominen, M., 2004. Risk management processes in supplier networks. International Journal of Production Economics 90 (1), 47-58.

Hallikas, J., Puumalainenb, K., Vesterinenb, T., Virolainenb, V., 2006. Riskbased classification of supplier relationships. International Journal of Production Economics 104, 201-213.

Harland, C., Brencheley, H., Walker, H., 2003. Risk in supply network. Journal of Purchasing and Supply Management 9 (2), 51-62.

Lamming, R., 1993. Beyond Partnership: Strategies for Innovation and Lean Supply. Prentice-Hall, Englewood Cliffs, NJ.

Link, P., 2001. risikomanagement von Innovationskooperationen. Doctoral Tesis, Nr. 14240, ETH Zurich, Zurich.

Link, P., Marxt, C., 2004. Integration of risk and chance management in the co-operation process. International Journal of Production Economics 90, 71-78.

Lo Nigro, G., Argoneto, P., Bruccoleri, M., Perrone, G., Renna, P., 2005. Horizontal co-operation in supply chain in an e-market environment. In: Proceedings of the International Manufacturing Leaders Forum on Global Competitive Manufacturing, 27th February-2nd March 2005, Adelaide, Australia.

Lo Nigro, G., Abbate, L., Bruccoleri, M., Perrone, G., 2007. How risk consideration can affect inter-organization relationship decisions. In: Proceedings of 19th International Conference on Production Research, 29/7-2/8 2007, Valparaiso (Chile).

March, J.G., Shapira, Z., 1987. Management perspective on risk and risk taking. Management Science 33 (11), 1404-1418.

Mazzarol, T., 1998. Partnerships: a key to growth in small business. In: 43rd ICSB Conference, Singapore.

Menard, C., 2004. The economics of hybrid organizations. Journal of Institutional and Theoretical Economics 160, 345-376.

Myerson, R.B., 1997. Game Theory. Harvard University Press.

Ojala, M., Hallikas, J., 2006. Investment decision-making in supplier networks: management of risk. International Journal of Production Economics 104, 201-213.

Powell, W.W., 1990. Neither market nor hierarchy: network forms of organization. Research in Organizational Behaviour 12, 295-336.

Ring, P.S., Van de Ven, A.H., 1992. Structuring cooperative relationship between organizations. Strategic Management Journal 13, 483-498.

Shapira, Z., 1995. Risk Taking: A Managerial Perspective. Russell Sage Foundation, New York.

Shapley, L.S., Shubik, M., 1954. A method for evaluating the distribution of power in a committee system. American Political Science Review $48,787-792$.

Sharpe, W.F., 1964. Capital asset prices: a theory of market equilibrium under conditions of risk. Journal of Finance 19, 425-442.

Smallman, C., 1996. Risk and organizational behaviour: a research model. Disaster Prevention and Management 5 (2), 12-26.

Spekman, R.E., Spear, J., Kamauff, J., 2002. Supply chain competency: learning as a key component. Supply Chain Management: An International Journal 7 (1), 41-55.

Tang, C.S., 2006. Perspectives in supply chain risk management. International Journal of Production Economics 103, 451-488.

Teece, D.J., Pisano, G., Shuen, A., 1997. Dynamic capabilities and strategic management. Strategic Management Journal 18 (7), 509-533.

Yates, J.F., Stone, E.R., 1992. The risk construct. In: Yates, J. (Ed.), Risk Taking Behaviour. Wiley, New York, pp. 1-25.

Yoshino, M.Y., Rangan, U.S., 1995. Strategic Alliances: An Entrepreneurial Approach to Globalization. Harvard Business School Press, Boston, MA.

Zsidisin, G.A., 2003. Managerial perceptions of supply risk. The Journal of Supply Chain Management 39 (1), 14-25. 